\title{
Mesosomes of Bacillus Species, Seen by Negative Staining
}

\author{
By P. J. HIGHTON, J. LLOYD AND MORAG WHITFIELD \\ Department of Molecular Biology, Kings' Buildings, Mayfield Road, \\ Edinburgh $\mathrm{EH}_{9}{ }_{3} \mathrm{JR}$
}

(Received 25 April 1973)

\section{INTRODUCTION}

A mesosome is an arrangement of membranes contained within an invagination of the plasma membrane. The mouth of the invagination opens to the space between the plasma membrane and the wall.

An electron-microscopic study of sections of Bacillus licheniformis 749C, prepared by the technique of Ryter \& Kellenberger (1958), showed that there was one mesosome per bacterium (Highton, 1969). Further, a correlation between the position of the mesosome in the bacterium and the length of the bacterium suggested that the mesosome doubled and divided together with the bacterium.

However, the appearance of whole bacteria, viewed by negative staining, did not fit this scheme at all. The number and size of mesosomes varied between the bacteria within a culture, and there was no correlation between the number of mesosomes and the bacterial length. The mesosomes were smaller than those seen after embedding, and the smaller they were, the more there were per bacterium.

Since the study by sectioning also showed that mesosomes were disrupted and redistributed within the bacterium as a result of plasmolysis produced by suspension in I M-sucrose before fixation, or simply by delayed fixation after harvesting, it was concluded that mesosomes were relatively fragile and were disrupted during negative staining. We have attempted to avoid disruption by using the fixation technique of Ryter \& Kellenberger (1958) before negative staining.

\section{METHODS}

Cultures. Bacillus licheniformis 749 (penicillinase inducible) and $749 \mathrm{C}$ (penicillinase constitutive) were grown from spores in CHS medium (Collins, 1964), at $37^{\circ} \mathrm{C}$, with aeration by shaking. Bacillus subtilis 168 and w23 were grown similarly in ' $S$ ' broth (Pollock, 1952). Cultures were harvested in the exponential phase at $E_{1 \mathrm{~mm}}=0.5$ at $675 \mathrm{~nm}$.

Specimen preparation. In the original method used for negative staining, a drop of culture was put on a carbon film supported on an electron microscope grid, a drop of stain added, and the liquid immediately drained off with filter paper. Staining was done at room temperature with $2 \%$ sodium phosphotungstate $(\mathrm{pH} 7 \cdot 0), 2 \%$ sodium silicotungstate $(\mathrm{pH} 7 \cdot 2)$ or $2 \%$ ammonium molybdate $(\mathrm{pH} 7 \cdot 2)$. In the modified procedure the bacteria were first prefixed according to the method of Ryter \& Kellenberger (1958). One per cent $\mathrm{OsO}_{4}$ in Michaëlis buffer ( $\mathrm{pH} \mathrm{6)}$ was added to a sample of the culture growing at $37^{\circ} \mathrm{C}$, to give a concentration of $0.1 \%$. The sample was immediately centrifuged and the bacteria resuspended in Michaëlis buffer ( $\mathrm{pH} \mathrm{6)}$ at room temperature. Bovine serum albumin (Sigma Chemical Co., St Louis, Missouri, U.S.A.) was added to give a concentration of $0.1 \%$ before negative staining.

Bacteria for sectioning were prefixed as above, fixed overnight in $\mathrm{OsO}_{4}$, washed in uranyl acetate, dehydrated in acetone, and embedded in Araldite as described previously (Highton, 


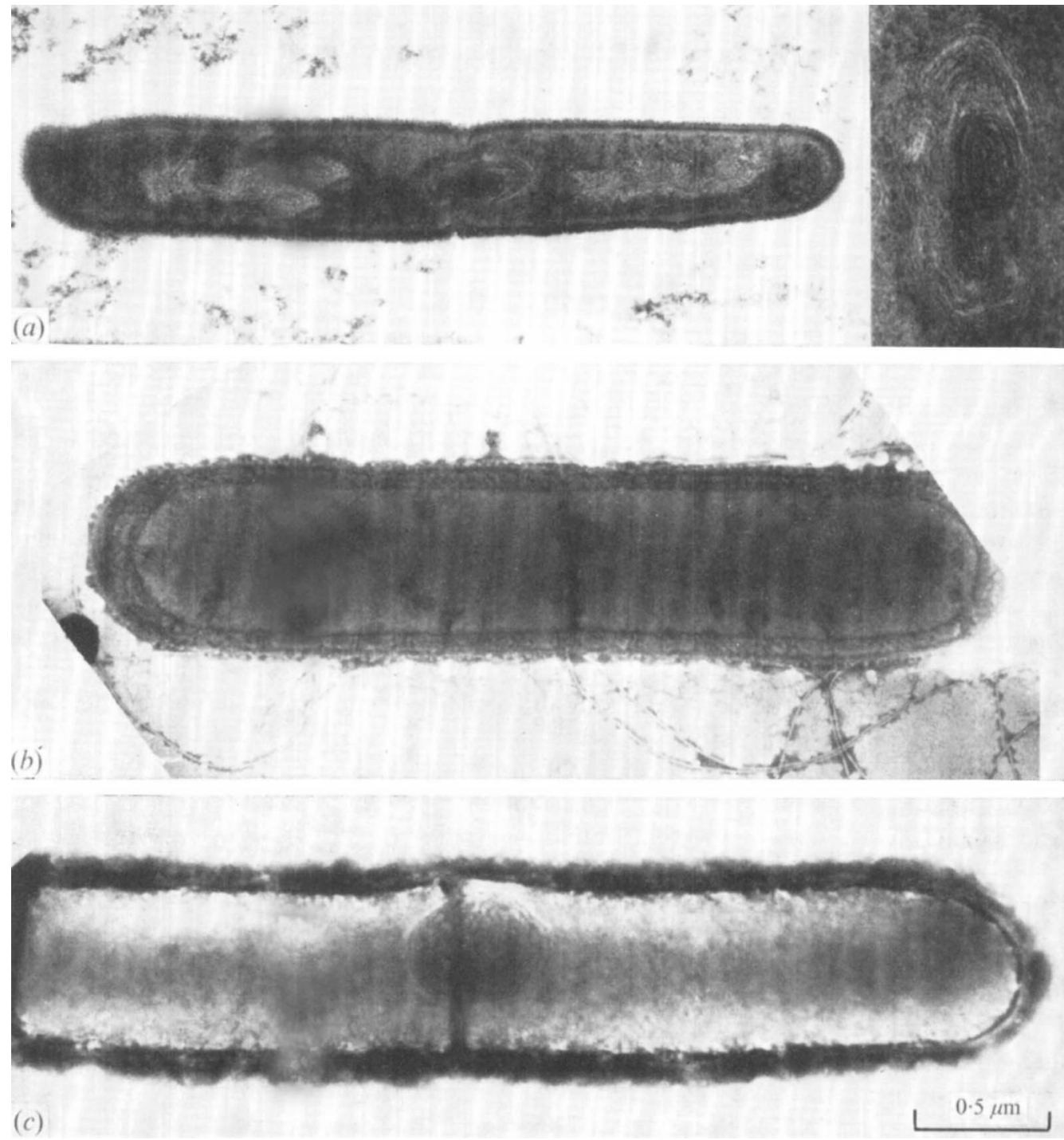

Fig. 1. Bacillus licheniformis $749 \mathrm{C}$ harvested in the exponential phase of growth. (a) A central longitudinal section, with the mesosome at $\times 2.5$ further magnification; $(b)$ a whole bacterium, negatively stained with sodium silicotungstate; $(c)$ a whole bacterium, prefixed with $\mathrm{OsO}_{4}$ and resuspended in $0.1 \%$ bovine serum albumin before being negatively stained with sodium phosphotungstate.

1969). Some samples for negative staining were also fixed overnight and washed in uranyl acetate as for embedding (see Results and Discussion).

Shadowing was done by evaporation of $\mathrm{Pt}$ at an angle of $\tan ^{-1} \frac{1}{8}$, and specimens were studied in a Siemens Elmiskop IOI and an Elmiskop IA.

\section{RESULTS AND DISCUSSION}

A central longitudinal section of Bacillus licheniformis $749 \mathrm{C}$, from a culture which was harvested in the exponential phase of growth, is shown in Fig. $I a$. There has probably been 
some distortion during embedding and sectioning, as the width is less than the average $(0.5 \mu \mathrm{m})$. The mesosome is in the middle, and is also shown at higher magnification.

A whole bacterium from an exponentially growing culture, negatively stained by simply mixing a drop of culture and a drop of stain on a carbon film, is shown in Fig. $\mathrm{I} b$. It is important to remember that although the bacterium presumably had a circular cross-section in solution, it will have been flattened on drying. Unidirectional shadowing showed that the thickness of bacteria perpendicular to the supporting film was about half the width seen. Further, the heavy metal stain will have dried around the bacterium, and within any surface pockets. The stain does not appear to have penetrated the plasma membrane, but has gone through the wall and into many invaginations of the plasma membrane, which are assumed to contain fragments of the mesosome. Stain has also been deposited in the groove formed in the wall where division was occurring. The structure around the edge of the bacterium is hard to interpret. Because of the thickness of the bacterium the structural detail is not sharp. The electron microscope was focused on the flagella in the lower part of the Figure. When printed, this area was exposed longer than the bacterium to make the flagella clearly visible.

In an attempt to reduce the structural damage assumed to have occurred during negative staining, the cultures were passed through the fixation stages used for embedding. They were then resuspended in buffer containing bovine serum albumin (BSA) to aid the spreading on the carbon film during negative staining.

Prefixation and fixation overnight in $\mathrm{OsO}_{4}$, with or without subsequent washing in uranyl acetate, made the bacteria very electron dense, even before negative staining, and it was hard to discern any internal structure after negative staining. However, prefixation alone produced less density increase, and most bacteria showed only one mesosome after negative staining (Fig. I $c$ ). These mesosomes were similar in dimensions to those seen in sections (Fig. I a). All three negative stains used gave this result. A survey of roo bacteria showed two with several additional smaller mesosomes, and one apparently without a mesosome. The remainder had only one mesosome. A similar reduction in the number of mesosomes was obtained with Bacillus licheniformis 749, and Bacillus subtilis I68 and W23.

The density from $\mathrm{OsO}_{4}$ and negative stain was such that high illumination was necessary, so that beyond the fringe of negative stain around the bacteria the photographic plates were completely blackened and showed no detail on printing, although, as with the bacterium in Fig. $\mathrm{x} b$, it was possible to focus the electron microscope on this area.

Unexpectedly, control samples showed that the presence of BSA during negative staining, even without prefixation, significantly reduced the number of mesosomes per bacterium, and increased their size to give an appearance between that in Fig. $\mathrm{I} b$ and that in Fig. I $c$. Prefixation, followed by negative staining without BSA, produced a similar result.

The carbon films used to support the bacteria were very hydrophobic and the solution was rapidly drained off by filter paper, but the addition of BSA greatly increased the wetting of the surface so that after draining, a thin layer of solution was left covering the surface. This layer was then allowed to dry. With the electron microscope, much protein was seen to have dried down between the bacteria. The modification of the drying process is assumed to have resulted in less damage and, together with the prefixation, to have prevented disruption of the mesosomes. The bacteria were still flattened however, judging by shadow length.

It is geometrically feasible that the 30 to 40 invaginations of the plasma membrane in Fig. I $b$ were formed around fragments of a single structure such as is shown in Fig. I $c$. For example, a spherical object can be divided into eight spheres with half the original diameter, or 64 with a quarter the diameter, etc. The stain only gives vague indications of the mesosome fragments within the invaginations, but as shown previously by sectioning, frag- 
ments produced on disruption move between the plasma membrane and the wall and the membrane invaginates around them.

These results are significant because negative staining is widely used for examining bacteria as it is extremely simple and quick. After harvesting, it is only a matter of minutes before the bacteria can be viewed in the microscope and photographs be taken. To prepare embedded material takes several days, and then an acquired skill is necessary to obtain sections. However, our results indicate that negative staining may be a very unreliable technique for studies on structures as large and complex as bacteria, unless accompanied by the study of sections.

\section{REFERENCES}

Collins, J. F. (1964). The distribution and formation of penicillinase in a bacterial population of Bacillus licheniformis. Journal of General Microbiology 34, 363-377.

Highton, P. J. (1969). An electron-microscopic study of cell growth and mesosomal structure in Bacillus licheniformis. Journal of Ultrastructure Research 26, $130-147$.

Pollock, M. R. (1952). Penicillinase adaptation in Bacillus cereus: an analysis of three phases in the response of logarithmically growing cultures to induction of penicillinase formation by penicillin. British Journal of Experimental Pathology 33, 587-600.

RYTER, A. \& Kellenberger, E. (I958). Étude au microscope électronique de plasmas contenant de l'acide désoxyribonucléique. Zeitschrift für Naturforschung 13, 597-605. 